\title{
Adherence to Antihypertensive Medications in Type 2 Diabetes: Prevalence and Determinants
}

\author{
Y. P. M. Van Camp ${ }^{1^{*}}$, B. Vrijens ${ }^{2,3}$, I. Abraham ${ }^{4}$, B. Van Rompaey ${ }^{1,5}$ \\ and M. M. Elseviers ${ }^{1}$
}

${ }^{1}$ Faculty of Medicine and Health Sciences, Universiteit Antwerpen, Centre for Research and Innovation in Care (CRIC), Wilrijk, Belgium.

${ }^{2}$ Department of Biostatistics and Medical Informatics, University of Liège, Liège, Belgium.

${ }^{3} \mathrm{MWV}$, Visé, Belgium.

${ }^{4}$ University of Arizona, Center for Health Outcomes and Pharmacoeconomic Research (HOPE), Tucson, Arizona, USA.

${ }^{5}$ Department of Healthcare, Artesis University College of Antwerp, Antwerp, Belgium.

\section{Authors' contributions}

This work was carried out in collaboration between all authors and all authors read and approved the final manuscript.

Original Research Article

Received ${ }^{\text {st }}$ April 2014

Accepted $4^{\text {th }}$ June 2014

Published 20 ${ }^{\text {th }}$ June 2014

\section{ABSTRACT}

Aim: To estimate the extent of non-adherence to antihypertensive drugs in type 2 diabetes.

Study Design: Observational.

Place and Duration of Study: The study was conducted at three Belgian specialised diabetes centres during two months.

Methodology: Included were adult type 2 diabetes patients, treated with insulin and either ACE-inhibitors or sartans. Adherence was assessed electronically with the Medication Event Monitoring System. A standardised blood pressure measurement was taken at the study start and end.

Results: Mean age of the 130 included patients was 65 and $51 \%$ was male. Mean $\mathrm{HbA} 1 \mathrm{c}$ was $7.5 \mathrm{mg} \%(59 \mathrm{mmol} / \mathrm{mol})$, mean BMI $32 \mathrm{~kg} / \mathrm{m} 2$ and mean daily oral pill burden 8. Half of the patients showed perfect adherence and another fourth missed the prescribed dose on only 1 of 56 days. Mean baseline blood pressure was $143 / 77 \mathrm{mmHg}$ and $25 \%$ had controlled blood pressure $(<130 /<80 \mathrm{mmHg})$. Higher hypertension 
knowledge was associated with adherence and higher daily doses of insulin with nonadherence. Adherence correlated positively to diastolic, but not systolic blood pressure. Of patients never missing a dose $78 \%$ reached controlled diastolic blood pressure compared to $68 \%$ of patients missing doses on $\geq 3$ days.

Conclusion: Adherence to antihypertensive medications was high in this cohort followed up at specialised diabetes centres. Still, about $15-20 \%$ had suboptimal adherence and should receive adherence enhancing support, especially since high adherence seems necessary to obtain blood pressure control.

Keywords: Diabetes; hypertension; medication; adherence.

\section{INTRODUCTION}

In type 2 diabetes blood pressure is as crucial as glycaemia control [1-3]. Hypertension in diabetes is common and associated with insulin resistance and vascular complications [1]. Type 2 diabetes patients are at a threefold higher risk of coronary artery and peripheral arterial disease and most deaths among them are attributable to cardiovascular disease [4]. Belgian type 2 diabetes patients who are prescribed at least two insulin injections per day are treated at specialised diabetes clinics, called convention centres, where they benefit of an intensive educational and follow-up programme by a multidisciplinary team [5]. In order to further optimise diabetes management they receive free blood glucose monitoring materials. The convention centres collaborate closely with the general practitioners. The general practitioners follow up hypertension treatment on a regular basis (e.g. medication prescription) and the convention centres follow up the general treatment once or twice a year (e.g. insulin dose).

Although antihypertensive medications are available, few type 2 diabetes patients reach blood pressure control. In general, only about $50 \%$ have a blood pressure $\leq 140 / 90 \mathrm{mmHg}$ $[2,6,7]$ while the threshold for controlled blood pressure in diabetes is even set at $130 / 80 \mathrm{mmHg}$ [1]. Non-adherence to antihypertensive treatment is often pointed to as the responsible factor and is reported to be ubiquitous in chronic illnesses. The World Health Organization reports a prevalence of $50 \%$ [8]. DiMatteo estimates the rate at $25 \%$ [9]. Among patients with hypertension non-adherence has a prevalence of $50 \%$ [10,11]. Whether medication non-adherence exists in all patients and to all types of medications is not fully known.

In type 2 diabetes the problem of non-adherence has been established in many treatment aspects [12-15]. Research on non-adherence to antihypertensive treatment is, however, scarce. In the few studies addressing the topic, the adherence measure is based on prescription refill data or self-report $[16,17]$ which are not the most reliable methods [18]. Self-report is a subjective adherence measure and in prescription refill measures there is no guarantee that dispensed medication is actually taken and a certain time delay exists between the actual filling of prescriptions and the consequent generation of adherence data [18].

The aim of the present study is 1) to estimate the extent of non-adherence to antihypertensive drugs in type 2 diabetes, measured electronically with the Medication Event Monitoring System (MEMS ${ }^{\circledR}$ ) and 2 ) to identify potential determinants. 


\section{MATERIALS AND METHODS}

\subsection{Study Design}

An observational cohort study was performed, measuring adherence to antihypertensive medications during two months. Patients, study personnel and caregivers remained blind for the adherence outcome. The diabetologists and diabetes educators of three Belgian, specialised diabetes convention centres recruited patients during three months. Eligible persons received a standard brochure with information about the study and were invited to return on one of the three starting dates, bringing their antihypertensive medications with them.

On the first study visit, participants signed the informed consent form and brought their antihypertensive medications for the next two months which were placed in a drug container. Drug containers were capped with a MEMS that records date and time of each opening of the package. Patients filled out the study questionnaires and had their blood pressure taken. At the second study visit, the study nurse read the dosing history data from the MEMS cap into computer and remeasured patients' blood pressure.

\subsection{Study Population}

Approval was obtained from the Ethics Committee of the Antwerp University Hospital (B300201111744). All patients at the participating diabetes centres were screened by study nurses between November 2011 and February 2012. Eligible were 1) adult (aged $\geq 18$ ), 2) type 2 diabetes patients, 3 ) treated with insulin, incretin hormone mimetics or analogues and 4) prescribed ACE-inhibitors or sartans. The exclusion criteria comprised 1) not self-administering medication care, 2) not speaking Dutch, 3) cognitive impairment, 4) nursing home residents or 5 ) diabetes treatment with pump therapy.

\subsection{Data Collection}

The baseline questionnaires surveyed 1) patients' demographics, 2) attitudes towards the antihypertensive treatment (perception of adverse events, belief in benefit and self-reported adherence), 3) knowledge, 4) social support and 5) health and quality of life (SF-36) [19]. Knowledge was assessed by a ten-item multiple-choice test on blood pressure, hypertension and antihypertensive treatment. The social support percentage was based on eleven questions assessing perceived support in diabetes in general and support with taking antihypertensive medications specifically. Medical and pharmacological data was gathered from patients' charts.

Primary outcome variable was adherence to ACE-inhibitors or sartans, derived from the MEMS (Fig. 1 [20]). Drug containers were filled with patients' ACE-inhibitors or sartans capped with MEMS. Patients were instructed to take them only and directly from the container at the time of intake and to open it only for an intake. The microchip in the MEMS cap registered date and time of each opening-and presumed intake. The dosing history data were read from the MEMS and centralised through a secured server. 


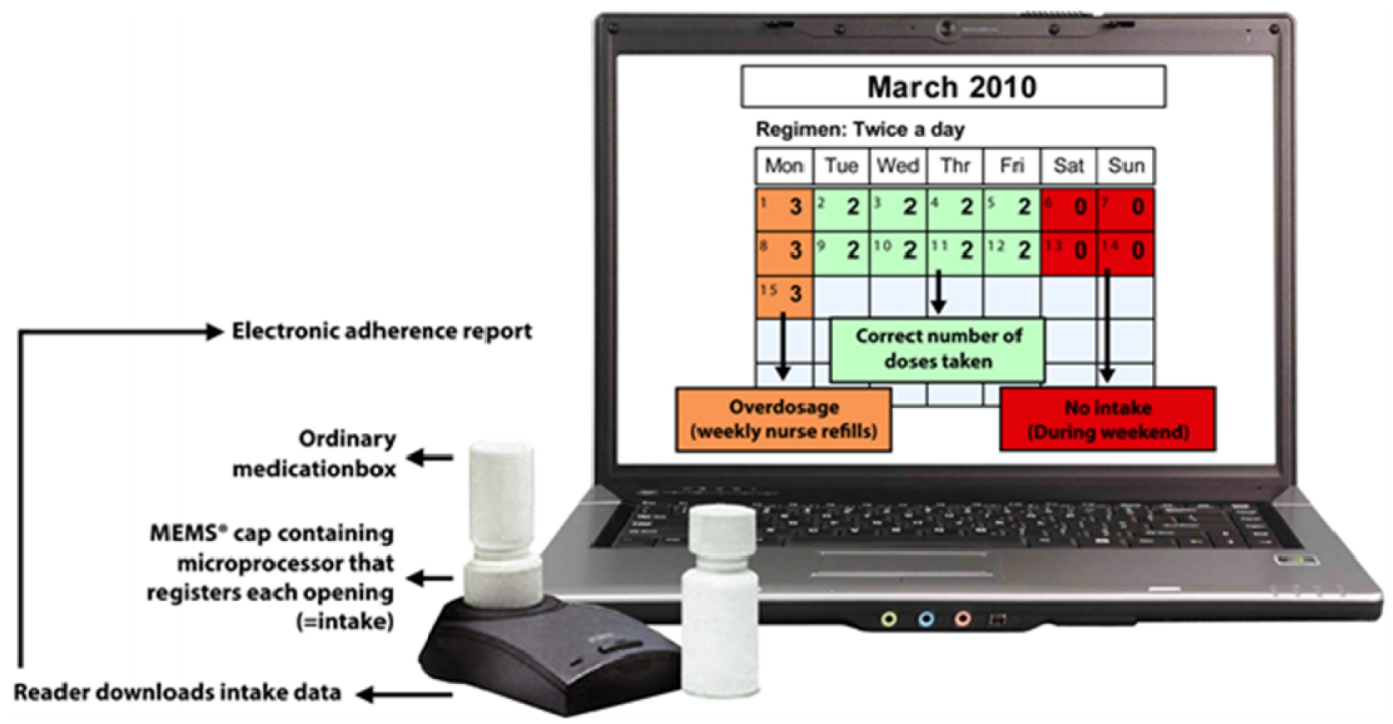

Fig. 1. Medication event monitoring system (MEMS $®)$ [20]

The secondary outcome, blood pressure, was measured in a standardised way. After a 5 minutes rest, three consecutive blood pressure measurements were taken at 15 seconds intervals. An automatic blood pressure monitor was placed at the right upper arm in a sitting position with the arm resting on a desk at heart level [21]. The three blood pressure measurements were averaged and dichotomised with blood pressure control defined as $<130 /<80 \mathrm{mmHg}[1]$.

\subsection{Data Analysis}

Data was analysed using IBM SPSS Statistics $20 \circledR$. The adherence data was corrected for medication changes and hospitalisation periods (excluded). Adherence was calculated by dividing the number of doses taken by the number of prescribed doses, averaged per week. Adherence was also dichotomised with being adherent defined as having missed prescribed dose(s) on no more than 3 out of the 56 days observed.

Differences between adherent and non-adherent patients were identified using independent samples t-tests and chi-square tests for continuous and categorical variables, respectively. Pearson's correlations were applied to calculate correlations between continuous variables. Differences and correlations were judged statistically significant when P-value $\leq 0.05$. Odd's ratios of influencing factors of non-adherence were calculated by logistic regression, building a multivariate model to identify the factors explaining the variance in adherence, with the significance of the odd's ratios judged by the $95 \% \mathrm{Cl}$.

\section{RESULTS AND DISCUSSION}

\subsection{Study Sample}

(Fig. 2) shows the patient flow. During the recruitment period, 1853 diabetes patients attended an appointment. The inclusion criteria were met by 665 patients, 118 of whom were 
excluded, yielding a total of 547 eligible patients. Of those, 137 showed interest in the study and returned to the first study visit. Five patients withdrew immediately after enrolment and two were excluded from the analyses because they continued to lay out their medications in advance, invalidating their MEMS adherence data. Thus, 130 patients were included in the analyses. With the exception of one patient with ACE-inhibitor treatment discontinuation in week 6 , there were no dropouts.

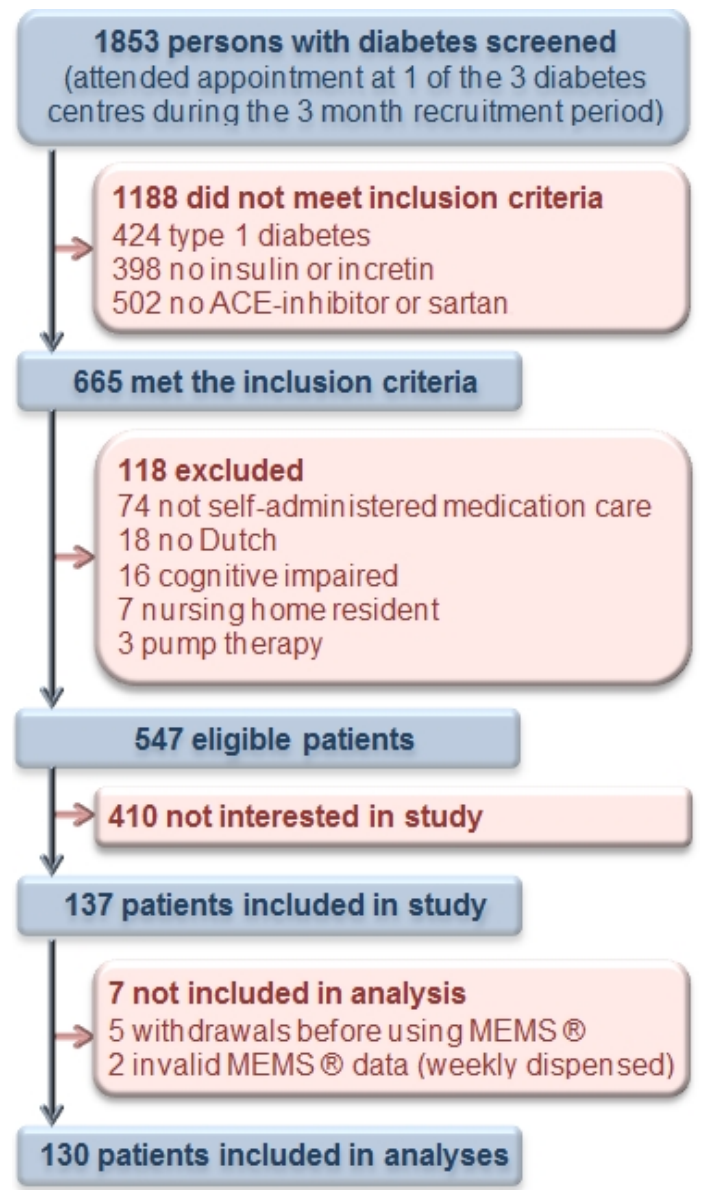

Fig. 2. Patient flow

The characteristics of the study subjects are listed in (Table 1). Mean age was 65 years and about half of the population was male. Most lived with their partner and were retired. Mean $\mathrm{H}_{\mathrm{b}} \mathrm{A} 1 \mathrm{c}$ was $7.5 \%(59 \mathrm{mmol} / \mathrm{mol})$ and mean $\mathrm{BMl} 31.9 \mathrm{~kg} / \mathrm{m}^{2}$. Most patients had a diabetes complication, $28 \%$ had retinal and $25 \%$ renal damage. Over half of the patients indicated to exercise seldom or never. Mean SF-36 scores were $50 \%$ (mental) and $43 \%$ (physical). The average score on the hypertension knowledge test was $59 \%$. Total mean daily pill burden amounted to 8 and $15 \%$ of the population used antidepressants. 
Table 1. Study subject characteristics

\begin{tabular}{|c|c|c|}
\hline \multicolumn{3}{|c|}{ Socio-demographic characteristics } \\
\hline \multirow{2}{*}{\multicolumn{2}{|c|}{$\begin{array}{l}\text { Age in years(mean(range })) \\
\text { Sex }(\% \text { male })\end{array}$}} & $65(39-87)$ \\
\hline & & 51 \\
\hline \multirow{3}{*}{$\begin{array}{l}\text { Living } \\
\text { situation }\end{array}$} & With partner & 53 \\
\hline & With partner \& children & 25 \\
\hline & Alone & 22 \\
\hline \multirow[t]{3}{*}{ Profession } & Retired & 66 \\
\hline & Working & 18 \\
\hline & None & 16 \\
\hline \multicolumn{3}{|c|}{ Social support score $(\operatorname{mean} \%(\mathrm{SD}))$} \\
\hline \multicolumn{3}{|c|}{ Pharmacological characteristics } \\
\hline \multicolumn{3}{|c|}{ ACE-inhibitor or sartan treatment } \\
\hline \multirow{2}{*}{\multicolumn{3}{|c|}{$\begin{array}{l}\text { Type: } \% \text { on ACE-inhibitor } \\
\text { Brands } 1\end{array}$}} \\
\hline & & \\
\hline \multicolumn{2}{|c|}{ Tritace® (\%) } & 22 \\
\hline \multicolumn{2}{|c|}{ Coversyl® $(\%)$} & 13 \\
\hline \multicolumn{2}{|c|}{ Regimen: \% on once a day } & 94 \\
\hline \multicolumn{2}{|c|}{ Adverse events(\%yes) } & 23 \\
\hline \multicolumn{2}{|c|}{ Belief in effectiveness(\%yes) } & 85 \\
\hline \multicolumn{2}{|c|}{ Self-reported adherence(\%yes) } & 78 \\
\hline \multicolumn{2}{|c|}{ Additional antihypertensive(\%yes) } & 67 \\
\hline \multicolumn{2}{|c|}{ Number of extra types (mean(SD)) } & $1.7(0.9)$ \\
\hline \multicolumn{2}{|c|}{ Beta-blockers(\%) } & 42 \\
\hline \multicolumn{2}{|c|}{ Calcium-antagonist $(\%)$} & 33 \\
\hline \multicolumn{2}{|c|}{ Diuretics(\%) } & 21 \\
\hline \multicolumn{2}{|c|}{ Total daily pill burden(mean(range)) } & $8(2-19)$ \\
\hline \multicolumn{2}{|c|}{ Chronic antidepressant use $(\%)$} & 15 \\
\hline \multicolumn{3}{|c|}{ Health characteristics } \\
\hline \multicolumn{2}{|c|}{ Blood pressure (BP) (mean mmHg) } & $143 / 77$ \\
\hline BP control & tart $(<130 / 80 \mathrm{mmHg})(\%)$ & 20 \\
\hline Systol & $\mathrm{P}$ control $(<130 \mathrm{mmHg})(\%)$ & 25 \\
\hline Diasto & BP control $(<80 \mathrm{mmHg})(\%)$ & 62 \\
\hline Years with & betes (mean(range)) & $15(1-49)$ \\
\hline $\mathrm{H}_{\mathrm{b}} \mathrm{A} 1 \mathrm{c}$ in $\%$ & ean(range)) & $7.5(5-13)$ \\
\hline $\mathrm{H}_{\mathrm{b}} \mathrm{A} 1 \mathrm{c}$ in $\mathrm{m}$ & I/mol (mean(range)) & $59(32-119)$ \\
\hline BMl in $\mathrm{kg} / \mathrm{n}$ & nean(range)) & $31.9(20.5-53.5)$ \\
\hline Diabetes c & plications (mean(SD)) & $0.7(0.8)$ \\
\hline Retina & ioyes) ${ }^{1}$ & 28 \\
\hline Renal & yes) ${ }^{1}$ & 25 \\
\hline Comorbidit & mean number(range)) & $3.4(0-6)$ \\
\hline Hype & ision(\%yes) & \\
\hline Alcohol-us & yes) & 50 \\
\hline Smoking(\% & & 11 \\
\hline Physical ac & ty $(\%)$ & \\
\hline Seldo & r never & 53 \\
\hline At lea & nce a week & 47 \\
\hline SF-36 (hea & and quality of life scale) & \\
\hline Menta & ore in \% (mean(range)) & $50(14-72)$ \\
\hline Physic & score in \% (mean(range) & $43(12-60)$ \\
\hline Knowledge & hypertension (mean\%(SD)) & $59(25)$ \\
\hline
\end{tabular}


Regarding the antihypertensive treatment $61 \%$ of the population took ACE-inhibitors and $39 \%$ sartans. The vast majority had a once a day regimen, about one fourth reported adverse events and most patients (85\%) believed in the effectiveness of the ACE-inhibitors or sartans. Additional antihypertensive medications, mostly beta-blockers, calciumantagonists and/or diuretics, were prescribed to $67 \%$ of patients.

\subsection{Adherence to Antihypertensive Medications}

(Fig. 3a) visualises the mean percentage of prescribed doses taken per week by all patients over two months. (Fig. 3b) shows boxplots of the mean adherence percentages per week. As the percentiles and whiskers all coincide in $100 \%$ we added the proportion of patients with perfect adherence (100\% prescribed doses taken) per week. Although the majority of patients never missed a single dose, the outliers indicate that every week 15 to $20 \%$ of the patients showed suboptimal adherence and were at risk of a lack of the ACE-inhibitors or sartans efficacy.

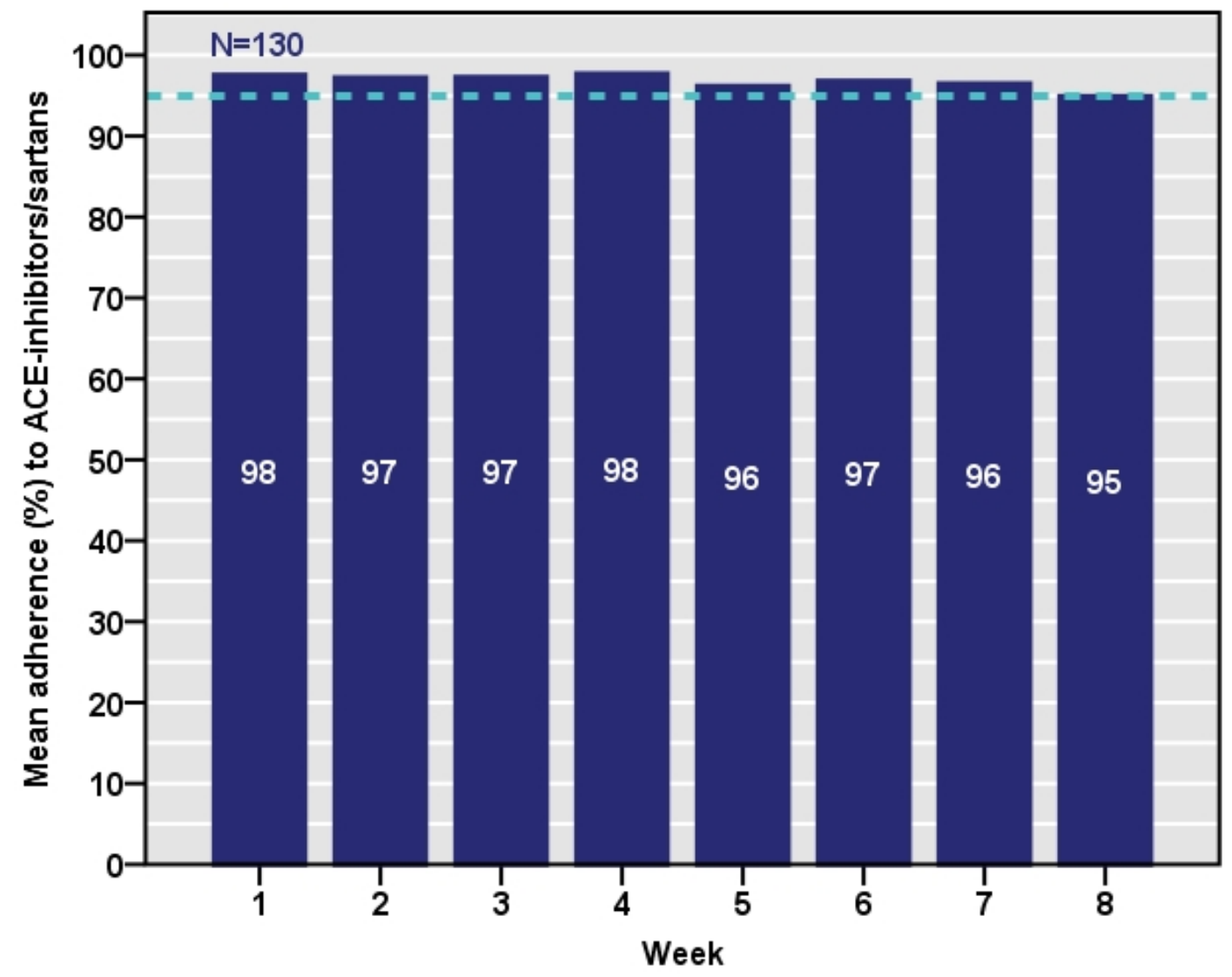

Fig. 3a. Mean percentage of adherence (prescribed doses taken) to ACE-inhibitors or sartans over two months 


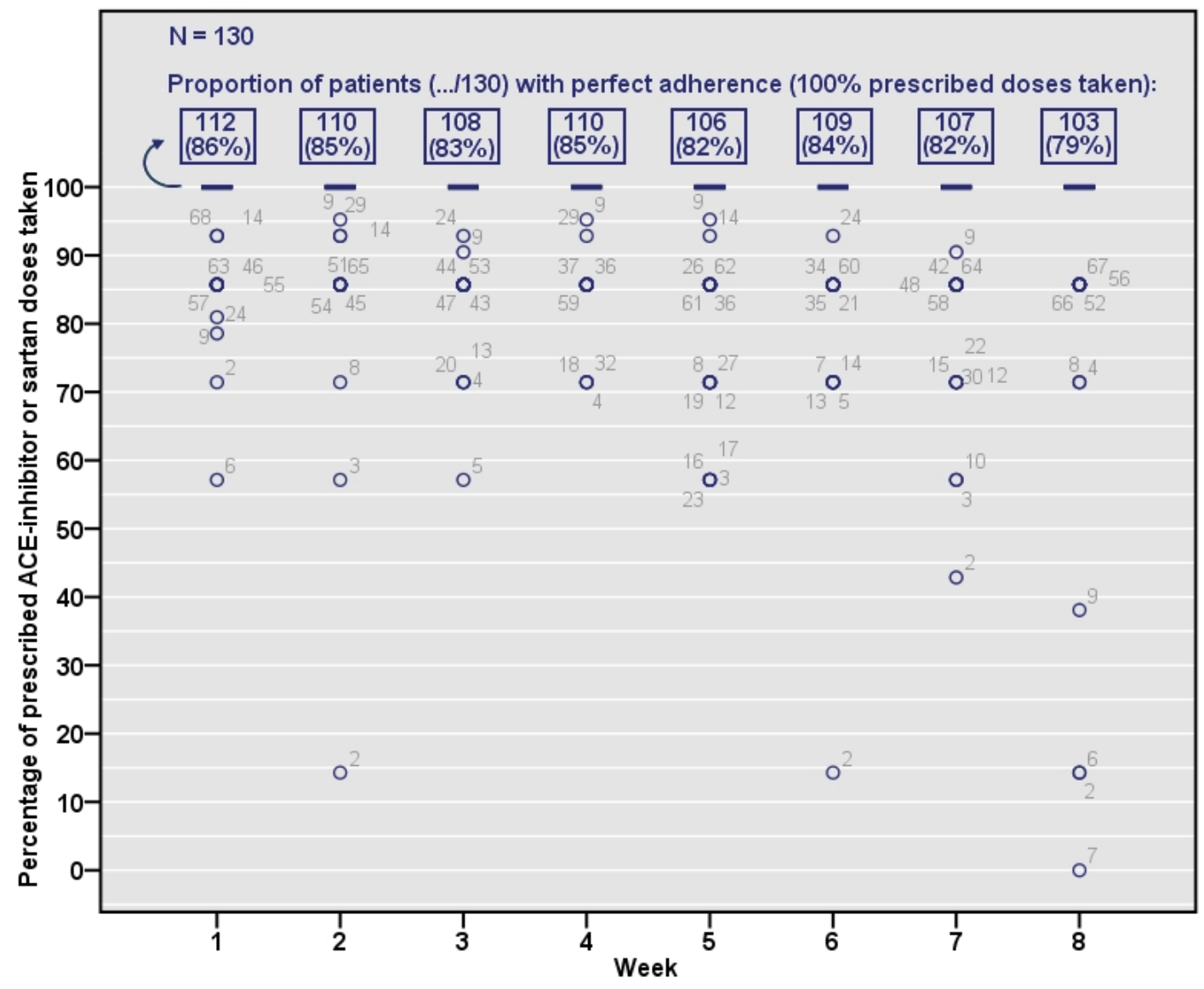

Fig. 3b. Boxplots per week of the percentage of prescribed ACE-inhibitor or sartan doses taken, with indication of the proportion of patients with perfect adherence ( $100 \%$ prescribed doses taken)

Over the eight weeks (56 days) period, nearly half of the patients (48\%) never missed a single dose. One fourth (24\%) missed the prescribed dose on 1 of the observed 56 days. Eight per cent missed 2 days of prescribed intake. The remaining $20 \%$ had 3 or more days on which the prescribed dose was not taken. The maximum number of days with a missed prescribed dose was nine.

\subsection{Blood Pressure}

At study visit 1 mean blood pressure of the included patients was $143 / 77 \mathrm{mmHg}$. One in five patients reached combined controlled systolic and diastolic blood pressure $(<130 /<80 \mathrm{mmHg}) ; 25 \%$ had a controlled systolic and $62 \%$ a controlled diastolic blood pressure.

At study visit 2 after 2 months patients' mean blood pressure was $137 / 74 \mathrm{mmHg}$ and $31 \%$ had a combined controlled systolic and diastolic blood pressure; $35 \%$ had a controlled systolic and $71 \%$ a controlled diastolic blood pressure. The differences of $-4 \mathrm{mmHg}$ in mean 
systolic and of $-3 \mathrm{mmHg}$ in diastolic blood pressure between study visit 1 and 2 were significant ( $P=.006$ and $P=.002$, respectively).

\subsection{Association between Adherence and Blood Pressure}

No correlation was found between systolic blood pressure and adherence $(P=.42)$. The correlation between diastolic blood pressure and adherence was significant but weak $(\mathrm{r}=0.068 ; P=.03 ; \mathrm{y}=-0.075 \mathrm{x}+81)$. (Fig. 4) shows the proportion of patients with controlled diastolic blood pressure $(<80 \mathrm{mmHg}$ at the second study visit after 2 months) per number of days with a missed dose (over the 2 months observation period). Of patients with perfect adherence (never having missed a single dose) $78 \%$ reached controlled diastolic blood pressure. Of patients having missed 3 or more days $64 \%$ had controlled diastolic blood pressure.

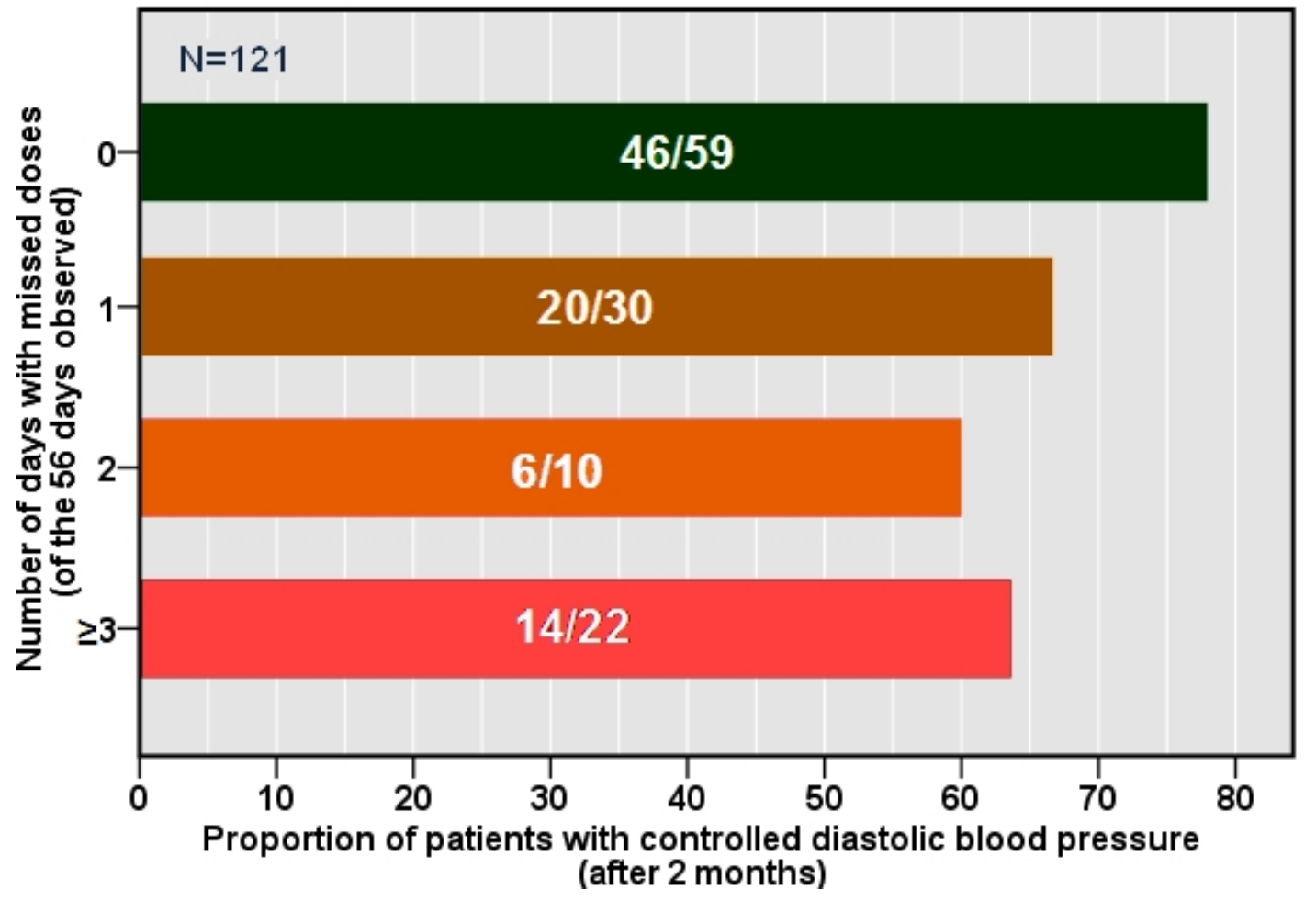

Fig. 4. Proportion of patients with controlled diastolic blood pressure (measured after 2 months) per number of days with a missed dose (over the 2 months observation period)

\subsection{Association between Self-reported and Electronically Measured Adherence}

Of the 130 patients 100 reported never to miss a single dose. In 47 of those 100 patients that reported perfect adherence the MEMS data showed a mean adherence percentage $<100 \%$ (Kappa=0.124; $P=.09$ ). The correlation of $r=0.231$ between self-reported adherence (always, mostly or mostly not) and mean adherence according to MEMS was significant 
$(P=.009)$. Patients self-reporting perfect adherence had 4.7 times the odds of missing no more than three day doses in the two months period $(95 \% \mathrm{Cl} 1.227-10.317)$.

\subsection{Determinants of Non-adherence to ACE-inhibitors or Sartans}

(Table 2) lists the influences of the studied variables on non-adherence (defined as having missed an intake on more than 3 of the 56 days observed). Sex and social support in diabetes proved to differ significantly between adherent and non-adherent patients. Only female sex-enhancing the odds of adherence-remained a significant determinant in the univariate analysis, yet not in the multivariate model. A once a day regimen (prescribed to $94 \%$ of the population) was a predictor of adherence in the model. Of the health characteristics, higher hypertension knowledge increased the likelihood of adherence. Higher daily doses of insulin and higher numbers of hospitalisations in the year preceding inclusion both decreased the odds of adherence.

In the multivariate model, three factors were retained: a once a day regimen, higher daily dose of insulin and hypertension knowledge. All three of them explained a fourth of the variance in adherence (Nagelkerke $r^{2}=0.25$ ). The odd's ratio of a once a day antihypertensive regimen did, however, have a relatively wide confidence interval with most patients having a once a day prescription.

\subsection{Discussion}

\subsubsection{Main findings}

Our study is among the first to find high adherence prevalences. Half of the patients never missed a single dose and another $24 \%$ only missed a dose on 1/56 observation days. Nonetheless, every week about 15 to $20 \%$ of patients showed suboptimal adherence. Further, we found high prevalences of uncontrolled blood pressure. We found an association between adherence to antihypertensive medications and diastolic, but not to systolic blood pressure. Of patients never missing a dose $78 \%$ reached controlled diastolic blood pressure compared to $68 \%$ of patients missing doses on $\geq 3$ days.

Higher hypertension knowledge enhanced the likelihood of adherence, whereas a higher daily dose of insulin decreased the odds.

\subsubsection{Prevalence of non-adherence}

We found quite a high adherence prevalence. The reason might be that the patients were recruited at specialised convention centres where high-risk diabetes patients are closely followed up [5,22]. Further, Belgian diabetes patients are followed up also in the primary care setting. General practitioners are responsible for blood pressure regulation on a regular basis and every (half) year patients return to the outpatient convention centre led by diabetes educators and diabetologists. Diabetes care is also quite self-managing oriented, which might also lead to self-control of concomitant treatments, such as the antihypertensive. Especially patients followed up at convention centres might be more aware of their condition and its progression and thus be motivated to control both condition and comorbidities like hypertension. Further, the predominant regimen of ACE-inhibitors and sartans in general, and in this study was quaque die, which has proven to contribute to adherence [23-25]. 
Table 2. Determinants of adherence to ACE-inhibitors or sartans

\begin{tabular}{|c|c|c|c|c|c|c|}
\hline & \multicolumn{3}{|c|}{ Descriptive } & \multicolumn{2}{|c|}{ Analytical } & \\
\hline & $\begin{array}{l}\text { Adherent* } \\
(\mathrm{N}=104)\end{array}$ & $\begin{array}{l}\text { Non-adherent** } \\
(\mathrm{N}=26)\end{array}$ & $\mathbf{p}$ & $\begin{array}{l}\text { Univariate Odd's } \\
\text { ratio }(95 \% \mathrm{Cl})\end{array}$ & $\begin{array}{l}\text { Multivariate } \\
\text { Odd's ratio }(95 \% \mathrm{Cl})\end{array}$ & \\
\hline \multicolumn{7}{|l|}{ Socio-demographics } \\
\hline Age: mean(SD) & $65(9)$ & $65(11)$ & 0.979 & $1.00(0.96-1.05)$ & & \\
\hline Sex: \%female & 53 & 31 & 0.039 & $2.58(1.03-6.46)$ & & \\
\hline Living situation: \%with children & 21 & 35 & 0.157 & $0.51(0.20-1.31)$ & & \\
\hline Profession: \%retired & 67 & 65 & 0.902 & $1.06(0.43-2.62)$ & & \\
\hline Social support score: mean\%(SD) & 72 & 67 & 0.323 & $1.01(0.99-1.03)$ & & \\
\hline Social support in general: \%yes & 88 & 73 & 0.050 & $2.79(0.97-8.03)$ & & 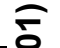 \\
\hline \multicolumn{6}{|l|}{ Pharmacological characteristics } & \\
\hline Regimen $^{1}: \%$ on once a day & 97 & 81 & 0.002 & 7.94(1.76-35.81) & $15.75(2.94-84.38)$ & 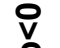 \\
\hline Adverse events $^{1}:$ \%yes & 20 & 32 & 0.213 & $0.54(0.21-1.43)$ & & 2 \\
\hline Belief in effectiveness 1 \% \%yes & 87 & 76 & 0.151 & $2.19(0.74-6.48)$ & & $\stackrel{1}{\mathrm{~N}}$ \\
\hline Total daily pill burden: mean(SD) & $7.6(3.2)$ & $8.4(4.5)$ & 0.306 & $0.94(0.84-1.06)$ & & 0 \\
\hline Antidepressant use: \%yes & 15 & 15 & 0.916 & $0.94(0.29-3.11)$ & & $y_{11}^{11}$ \\
\hline \multicolumn{6}{|l|}{ Health characteristics } & \\
\hline Years with diabetes: mean(SD) & $14(9)$ & $16(10)$ & 0.543 & $0.99(0.94-1.03)$ & & $\underline{\underline{y}}$ \\
\hline Daily dose of insulin: mean(SD) & $54(31)$ & $75(62)$ & 0.012 & $0.99(0.98-0.99)$ & $0.99(0.97-0.99)$ & $\stackrel{\oplus}{=}$ \\
\hline BMI: mean(SD) & $32.3(5.6)$ & $30.1(5.0)$ & 0.075 & $1.09(0.99-1.20)$ & & O \\
\hline Diabetes complications: mean(SD) & $0.6(0.7)$ & $0.9(1.0)$ & 0.197 & $0.66(0.39-1.11)$ & & $\frac{\pi}{2}$ \\
\hline Comorbidities: mean(SD) & $3.4(0.9)$ & $3.4(1.0)$ & 0.985 & $1.01(0.64-1.58)$ & & \\
\hline Hospitalisations <year: mean(SD) & $0.5(0.9)$ & $1.4(3.0)$ & 0.009 & $0.69(0.46-1.02)$ & & \\
\hline Alcohol use: \%yes & 47 & 64 & 0.119 & $0.49(0.20-1.21)$ & & \\
\hline Smoking: \%yes & 12 & 8 & 0.640 & $1.45(0.30-6.96)$ & & \\
\hline Physical activity: \%seldom/never & 45 & 58 & 0.234 & $1.69(0.71-4.03)$ & & \\
\hline SF-36 mental score: mean(SD) & $51(11)$ & $47(11)$ & 0.091 & $1.03(0.99-1.07)$ & & \\
\hline SF-36 physical score: mean(SD) & $42(12)$ & $44(10)$ & 0.425 & $0.96(0.95-1.03)$ & & \\
\hline Knowledge 2 mean(SD) & $62(25)$ & $48(24)$ & 0.011 & $1.02(1.01-1.04)$ & $1.03(1.01-1.05)$ & \\
\hline
\end{tabular}


The relatively low response rate might also have contributed to the high adherence figures. Originally, this study was set up as a one year randomised controlled trial, asking patients to return bi-monthly to the diabetes centre. The purpose was to randomise patients and test a nurse-led adherence enhancing intervention after the two-month observational baseline period (on which we reported here). Still, only $20 \%$ of the patients had a controlled blood pressure and still all of them agreed to participate in the study. Also, in many other studies the same recruitment method was applied with often low response rates and still high prevalences of non-adherence reported [26]. A follow-up study started fall 2012, applying similar methods, but with a consecutive sample to decrease selection bias to concur the findings of this study.

\subsubsection{Factors associated with non-adherence}

The once a day regimen was retained as a factor increasing the odds of adherence in both our uni-and multivariate analyses but $94 \%$ of patients were on this regimen. Other factors retained were, not surprisingly, higher hypertension knowledge, corroborating existing literature [27-30]. We also found higher daily doses of insulin decreasing the odds of adherence, which might indicate that patients experiencing difficulties adhering to their diets and insulin treatment are also more likely not to adhere to their medication treatment. However, similar correlations were not found in other health-related habits such as BMI, physical exercise or smoking.

\subsubsection{Adherence measurement}

Our adherence measurement was restricted to the proportion of prescribed drugs taken (intake adherence), recently called the implementation of drug prescription [31]. We did not measure other adherence components, such as initiation (taking the first prescribed dose) or the number of doses taken on time. First, our aim was specifically to assess the implementation of drug prescriptions and as patients are encouraged by their caregivers to link the intake to daily habits such as breakfast, the intake might fluctuate in time. Second, most anti hypertensives have a forgiveness with substantially differing capacity depending on their pharmacokinetic (from six hours for Atenolol to a couple of days for Aiskiren). For these reasons timing adherence was not worth to be further explored here, unlike in case of HIV-medications for instance, where timing adherence is as crucial as taking adherence [32].

\subsubsection{Blood pressure control}

In line with previous studies, we found that few diabetes patients achieve blood pressure control $[2,6,7]$. Compared to the first visit, patients did show significantly better blood pressure outcomes at the second study visit, probably attributable to a white coat effect. As established in previous research especially systolic blood pressure control was problematic $[33,34]$, with only $25 \%$ achieving it. Systolic blood pressure control proves especially challenging in middle-age and older patients, in whose case it is associated with increased arterial stiffness that appears less amenable to current therapies [35]. Although diastolic blood pressure was historically thought to be the strongest predictor of cardiovascular events, systolic blood pressure confers a greater risk and should be the primary (and to some even the only) focus of therapy $[36,37]$. Still, today, treatment guidelines lay the emphasis on both. Alternatively, the cut-off value of $<80 \mathrm{mmHg}$ for controlled diastolic blood pressure might be questioned but even when raising the threshold to $<90 \mathrm{mmHg}$, half of the patients did not reach systolic pressure control (not reported in the result section). 
In the same line, we found that higher adherence to ACE-inhibitors or sartans was associated with diastolic, but not with systolic blood pressure. Of patients never missing a dose $78 \%$ reached controlled diastolic blood pressure compared to $68 \%$ of patients missing doses on $\geq 3$ days. Improving adherence shows to be an important factor in achieving diastolic blood pressure control and should be a priority in the care for (diabetes) patients suffering from hypertension.

\section{CONCLUSION}

Adherence to ACE-inhibitors or sartans was high in this cohort of type 2 diabetes patients at specialised convention centres. Although the majority had good adherence, about 15 to $20 \%$ of the patients showed suboptimal adherence and should be supported to improve their medication intake, especially since high adherence seems necessary to obtain blood pressure control. Health care workers should focus on intake behaviour and inform patients about the consequences of-even occasionally-missing a dose. Even in our population showing (nearly) perfect adherence, (too) many diabetes patients had an uncontrolled blood pressure. The reason why high adherence is not translated into controlled blood pressure is to be further explored.

\section{CONSENT}

All authors declare that written informed consent was obtained from the patient (or other approved parties) for publication of this case report and accompanying images.

\section{ETHICAL APPROVAL}

The authors have obtained all necessary ethical approval from suitable Institutional or State or National or International Committee. Approval was obtained from the Ethics Committee of the Antwerp University Hospital (B300201111744).

\section{COMPETING INTERESTS}

Authors have declared that no competing interests exist.

\section{REFERENCES}

1. Standards of Medical Care in Diabetes-2012. Diabetes Care. 2012;35(1):S11-S63.

2. Bohme P, Khiter S, Giesenfeld A, May I, Guerci B, and Ziegler O. Practices and benefits of antihypertensive treatment in patients with type 2 diabetes followed in CHU: comparison with the cohort ENTRED. Diabetes Metab. 2012;38:A96-A96.

3. Tillin T, Orchard T, Malm A, Fuller J, Chaturvedi N. The role of antihypertensive therapy in reducing vascular complications of type 2 diabetes. Findings from the Diabetic $R$ Etinopathy Candesartan Trials-Protect 2 study. J Hypertens. 2011;29(7):1457-1462.

4. Beckman JA, Creager MA, Libby $P$. Diabetes and atherosclerosis-epidemiology, pathophysiology and management. JAMA-J Am Med Assoc. 2002;287(19):2570-2581.

5. Nobels F, Scheen AJ. The role of diabetes convention centres in Belgium. Revue medicale de Liege. 2005;60(5-6):619-23.

6. Berthold HK, Bestehorn KP, Krone W, Gouni-Berthold I. Atherosclerotic disease location and disparities in the control and treatment of cardiovascular risk factors in patients with Type 2 diabetes. Diabetic Med. 2010;27(3):303-308. 
7. Godley PJ, Maue SK, Farrelly EW, Frech F. The need for improved medical management of patients with concomitant, hypertension and type 2 diabetes mellitus. Am J Manag Care. 2005;11(4):206-210.

8. World Health Organisation. Adherence to long-term therapies: Evidence for action. Geneva, Switzerland; 2003.

9. DiMatteo MR. Variations in patients' adherence to medical recommendations-A quantitative review of 50 years of research. Med Care. 2004;42(3):200-209.

10. Vrijens B, Vincze G, Kristanto P, Urquhart J, Burnier M. Adherence to prescribed antihypertensive drug treatments: Longitudinal study of electronically compiled dosing histories. Br Med J. 2008;336(7653):1114-1117.

11. Hill MN, Miller NH, DeGeest S, Amer Soc Hypertension Writing G. ASH Position Paper: Adherence and Persistence with taking medication to control high blood Pressure. J Clin Hypertens. 2010;12(10):757-764.

12. Peeters B, Van Tongelen I, Boussery K, Mehuys E, Remon JP, Willems S. Factors associated with medication adherence to oral hypoglycaemic agents in different ethnic groups suffering from Type 2 diabetes: A systematic literature review and suggestions for further research. Diabetic Med. 2011;28(3):262-275.

13. Peyrot M, Barnett AH, Meneghini LF, Schumm-Draeger PM. Insulin adherence behaviours and barriers in the multinational global attitudes of patients and physicians in insulin therapy study. Diabetic Med. 2012;29(5):682-689.

14. Donnelly LA, Doney ASF, Morris AD, Palmer CNA, Donnan PT. Long-term adherence to statin treatment in diabetes. Diabetic Med. 2008;25(7):850-855.

15. Boas L, Foss MC, Foss-Freitas MC, Torres HD, Monteiro LZ, Pace AE. Adherence to diet and exercise among people with diabetes mellitus. Texto Contexto Enferm. 2011;20(2):272-279.

16. Shaw R, Bosworth HB. Baseline medication adherence and blood pressure in a 24month longitudinal hypertension study. J Clin Nurs. 2012;21(9-10):1401-1406.

17. Wang Z, Walton SM, Lee TA, Pickard AS. Patient adherence with anti diabetic, antihypertensive and lipid-lowering medications: Evaluation of veterans with type 2 diabetes. Value Health. 2006;9(3):A138-A138.

18. Osterberg L, Blaschke T. Drug therapy- adherence to medication. $\mathrm{N}$ Engl J Med. 2005;353(5):487-497.

19. Aaronson NK, Muller M, Cohen PDA, Essink-Bot ML, Fekkes M, Sanderman R, et al. Translation, validation and norming of the Dutch language version of the SF-36 Health Survey in community and chronic disease populations. J Clin Epidemiol. 1998;51(11):1055-1068.

20. Van Camp YP, Huybrechts SA, Van Rompaey B, Elseviers MM. Nurse-led education and counselling to enhance adherence to phosphate binders. J Clin Nurs. 2012;21(910):1304-1313.

21. Mancia G, De Backer G, Dominiczak A, Cifkova R, Fagard R, Germano G, et al. Guidelines for the management of arterial hypertension-the task force for the management of arterial hypertension of the European society of hypertension (ESH) and of the European society of cardiology (ESC). Eur Heart J. 2007;28(12):1462-1536.

22. Sunaert P, Bastiaens H, Nobels F, Feyen L, Verbeke G, Vermeire E, et al. Effectiveness of the introduction of a chronic care model-based program for type 2 diabetes in Belgium. BMC Health Serv Res. 2010;10.

23. Conn VS, Hafdahl AR, Cooper PS, Ruppar TM, Mehr DR, Russell CL. Interventions to improve medication adherence among older adults: Meta-analysis of adherence outcomes among randomized controlled trials. Gerontologist. 2009;49(4):447-462. 
24. Zeng F, Patel BV, Andrews L, Frech-Tamas F, Rudolph AE. Adherence and persistence of single-pill $A R B / C C B$ combination therapy compared to multiple-pill ARB/CCB regimens. Curr Med Res Opin. 2010;26(12):2877-2887.

25. Hussein MA, Chapman RH, Benner JS, Tang SSK, Solomon HA, Joyce A, Foody JM. Does a single-pill antihypertensive/lipid-lowering regimen improve adherence in US managed care enrolees? A non-randomized, observational, retrospective study. Am J Cardiovasc Drugs. 2010;10(3):193-202.

26. DiMatteo MR, Giordani PJ, Lepper HS, Croghan TW. Patient adherence and medical treatment outcomes-a meta-analysis. Med Care. 2002;40(9):794-811.

27. Shi LZ, Liu JA, Fonseca V, Walker P, Kalsekar A, Pawaskar M. Correlation between adherence rates measured by MEMS and self-reported questionnaires: A metaanalysis. Health Qual Life Outcomes. 2010;8:12-18.

28. Al-Qazaz HK, Sulaiman SA, Hassali MA, Shafie AA, Sundram S, AI-Nuri R, Saleem F. Diabetes knowledge, medication adherence and glycemic control among patients with type 2 diabetes. Int J Clin Phar. 2011;33(6):1028-1035.

29. Charland SL, Agatep BC, Epstein RS, Frueh FW, Herrera V, Devlin J, et al. Patient knowledge of pharmacogenetic information improves adherence to statin therapy: results of the additional KIF6 risk offers better adherence to statins (AKROBATS) trial. J Am Coll Cardiol. 2012;59(13):E1848-E1848.

30. Karaeren H, Yokusoglu M, Uzun S, Baysan O, Koz C, Kara B, et al. The effect of the content of the knowledge on adherence to medication in hypertensive patients. Anadolu Kardiyol Derg. 2009;9(3):183-188.

31. Vrijens B, De Geest S, Hughes DA, Kardas P, Demonceau J, Ruppar T, et al. A new taxonomy for describing and defining adherence to medications. British Journal of Clinical Pharmacology; 2011.

32. Vrijens B, Goetghebeur E, de Klerk E, Rode R, Mayer S, Urquhart J. Modelling the association between adherence and viral load in HIV-infected patients. Stat Med. 2005;24(17):2719-2731.

33. Waeber B, Mourad JJ. Targeting systolic blood pressure: The key to controlling combined systolic/diastolic hypertension. Am J Hypertens. 2006;19(9):985-986.

34. Joseph LA, Castro J, Khorrami S, Sennimalai G, Gosukonda P, Deshmukh M, et al. A cross sectional and longitudinal analysis of systolic and diastolic blood pressure control in diabetic patients. Am J Hypertens. 2004;17(5):47A-47A.

35. Franklin SS. Systolic blood pressure-it's time to take control. Am J Hypertens. 2004;17(12):49S-54S.

36. Weir MR. Assessing the blood pressure-lowering efficacy of antihypertensive medications: Which blood pressures should we use? J Clin Hypertens. 2009;11(3):155-158.

37. Hebert CJ, Shidham G, Hebert LA. Should the target for blood pressure control specify both a systolic and a diastolic component? Curr Hypertens Rep. 2005;7(5):360-362.

(C) 2014 Camp et al.; This is an Open Access article distributed under the terms of the Creative Commons Attribution License (http://creativecommons.org/licenses/by/3.0), which permits unrestricted use, distribution, and reproduction in any medium, provided the original work is properly cited.

\section{Peer-review history:}

The peer review history for this paper can be accessed here: http://www.sciencedomain.org/review-history.php?iid=579\&id=12\&aid=5021 